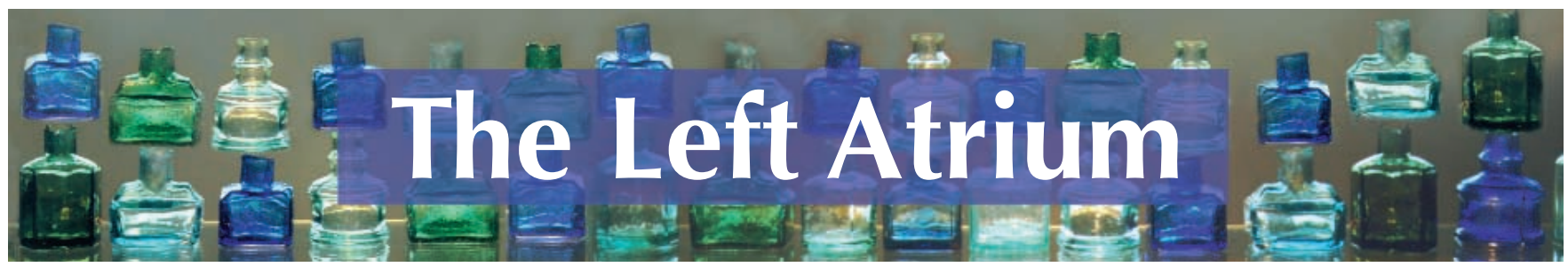

\section{So many books, so little time}

The doctor in literature: satisfaction or resentment?

Solomon Posen

Oxford: Radcliffe Publishing; 2005

298 pp \$71.50 (paper) ISBN 1-85775-609-6

A $t$ the risk of being banal, let me reiterate that we live in an information age. We are more and more "plugged in," and some of us, if we're not exactly paperless, are at least using paper less. I receive electronic "infoPOEMS" from the CMA, by means of which I am kept just a wee bit more in the loop vis-à-vis current evidence (a highly suspicious word). I have Griffith's 5-Minute Clinical Consult on my trusty Palm Pilot and can report that the Palm version of the Sanford Guide to Antimicrobial Therapy is only slightly less difficult to read than the notoriously small-printed pocket guide. But you know, it's nice to not have to lug around 3 or 4 coil-ringed, dog-eared, coffee-stained volumes, especially as these invariably found their way into the already overburdened pockets of my formerly crisp and clean white coat.

In an era of information overload, or "data flak" (to borrow an expression from William Leiss's 1990 book Under Technology's Thumb), many would have us believe that it is as important to know how and where to find information as it is to have it synthesized in our minds. And if we don't even know where to start with a topic, we can simply "google." And this, of course, raises the question, what of erudition? (Yes, it too can be "googled.")

All of which is by means of an introduction to a new reference book by Australian endocrinologist Solomon Posen. The Doctor in Literature: Satisfaction or Resentment? promises to be the first of a series of four volumes exploring physicians as depicted in modern literature. Posen clearly has done his homework and, drawing on similar earlier works, has put together a rich cata-

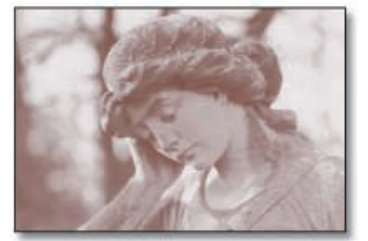

logue, which he offers as a "junior companion to Huth and Murray's magnificent Medicine in Quotations."

Keeping in mind the adage about squeaky wheels, it should come as no surprise that Posen's introductory comments prepare the reader for the fact that, although most interactions between physicians and patients end well, "in a minority of cases ... this happy state is not achieved, and it is this minority which predominates in fictional accounts of doctors." Posen continues, "while the practice of medicine has changed profoundly over the years, the patients' grievances have not."

Although I am confused as to why it is so expensive, this is a great book: referenced, readable and replete with both obscure and well-known examples of fictional physicians. Each chapter is devoted to a different aspect of the physician's life and work. For example, there's a fabulous chapter devoted to ward rounds, a lengthy discussion of the physician's fee, a chapter each given to bedside manner and to histories and physicals, and of course a chapter entitled "Treatment: successes and failures." There are useful chapter summaries and brief and lengthy quotations enough to give the reader both the content and the flavour of the work being described.

Posen writes with "the 'correct' degree of attachment," I would say, which is appropriate given that this is one of his chapter titles. Although he cannot but have an agenda, he is evidently at pains to present "just the facts"; he neither scorns nor praises his profession, neither defends nor attacks outright the situations and practices he adumbrates. Rather, Posen has done a nice job of cataloguing and indexing the literature he has reviewed, and he goes some way toward using this book as a social history of medicine. He refers to "[Dr.] Jimmy Kildare and his clones" as medical cowboys, wearing white coats instead of white hats, but always "fighting the forces of darkness and ignorance, and mostly coming out victorious." Importantly, Posen notes,

Kildare and his successors rarely have to deal with chronic or untreatable illnesses, with hopelessly retarded children or with patients who get worse instead of better. Shem's cynical and grotesque House of God and Dooling's Gothic Critical Care, with their medical caricatures, are obviously part of a reaction against the genre of "Medical Westerns."

Notwithstanding the constant back and forth of the medical pendulum (is Poe here invoked? He's not in Posen's index, although one can find "poltroons,

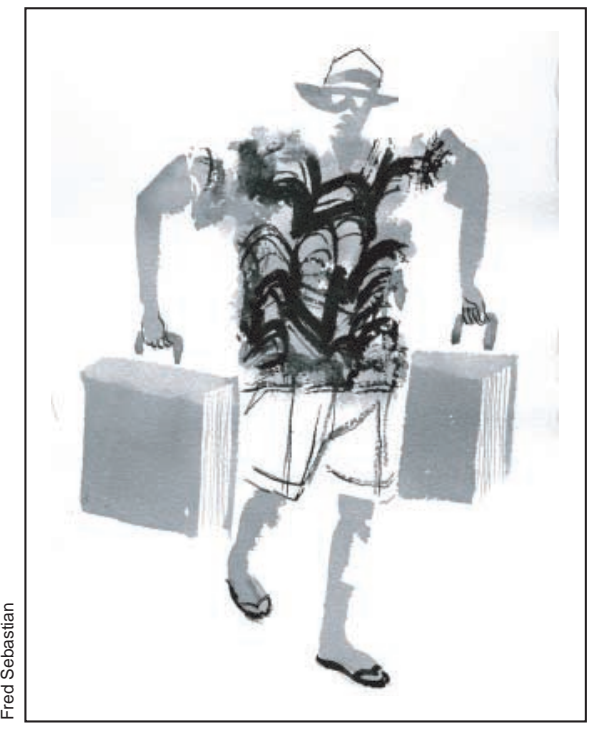

medical"), Posen's research demonstrates that "there is an astonishing continuity of the doctor-patient relationship, as described in fictional literature, across geographic and historical boundaries $[, \ldots$ and $]$ when this relationship is suboptimal, the patients' complaints two thousand years ago seem almost identi- 
cal with those heard in the twenty-first century."

But let me leave you with a concern, a certain gnawing disquiet I feel whenever I have to choose between reading Harrison's/Cecil/NMS or Le Carré/ Rendell/James. To be sure, as Posen points out, "one does not go to fiction for help with diagnostic or therapeutic problems," but where better do we see the human condition splayed open for us than in great writing? And this takes me back to my question regarding erudition. For what is erudition? Is it an accumulation of lived wisdom, or is it the ability to pepper our thoughts and writings with references plucked from electronic databases and indexes such as that prepared here by Posen? If we read Posen, and then proceed to the sources he thoroughly records, this volume will have served a useful purpose. If not, I wonder if it's not just more data flak.

\section{Edward E. St. Godard \\ PGY2 \\ Family Medical Centre \\ University of Manitoba \\ Winnipeg, Man.}

\section{Lifeworks}

\section{Retrospective on nursing}

A caring profession: centuries of nursing in Canada Christina Bates, Principal Curator Canadian Museum of Civilization Gatineau, Quebec

June 17, 2005 - Sept. 4, 2006

W hen the Canadian Nurses Association (CNA) announced in 1998 that it was closing its in-house library and archives, the decision was met with a mix of indignation and sadness by many nurses familiar with the collection. Intellectually, I expect, they accepted the fact that maintaining a collection is a costly endeavour; and, clearly, space at CNA House in Ottawa was at a premium. Emotionally, though, there was a sense that the nursing profession risked losing control of its own history and of the many artifacts and documents that helped tell its story.

Despite letters of protest from within its ranks, the CNA remained firm in its decision. Over a number of months the collection was assessed, and the library and archives were gradually dismantled. Eventually, the association struck a partnership with the Canadian Museum of Civilization (CMC), the $\circ$ Canadian War Museum and Library and Archives Canada - one that saw the collection divided up and distributed appropriately among these three institutions. Meanwhile, the CNA tried to reassure its members that the move would ultimately guarantee broader ac- cess to the collection for nurses and the public alike.

Today, there is every indication that this has been accomplished. In June 2004 the CMC, with its partners and using funds raised by the CNA and the Canadian Nurses Foundation, launched the Canadian Nursing History Collection Online, which provides Internet access to nearly 2000 artifacts relating to civilian and military nursing. Now comes $A$ Caring Profession: Centuries of Nursing in Canada, a sweeping exhibit that will run until Sept. 4, 2006, at the Canadian Museum of Civilization in Gatineau, Quebec. Its principal curator is Christina Bates, CMC's Ontario Historian and Assistant Director, Archaeology and History.

By the museum's description, A Caring Profession is "the most extensive exhibition to examine the impact of nursing on the lives of Canadians." Organized in nine sections and highlighting an array of personalities, it is a fascinating trip through time, geography and nursing

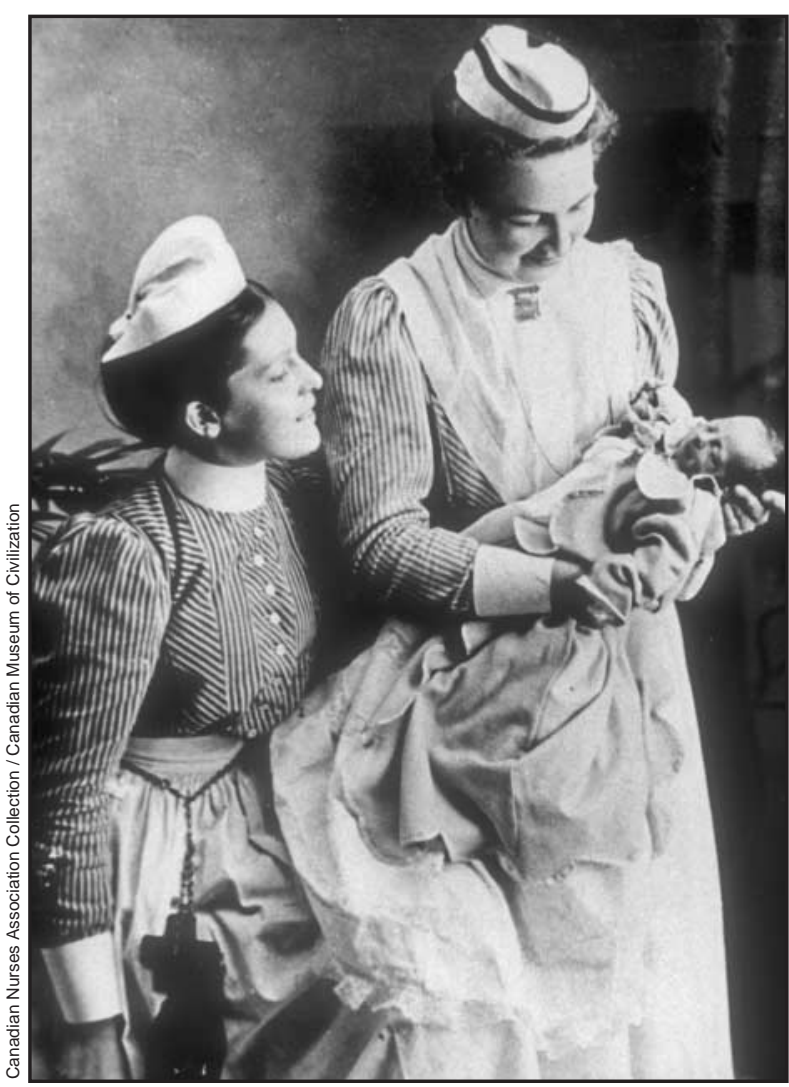

Student and graduate nurse, Mack Training School for Nurses, St. Catharines, Ontario, circa 1901. 